\title{
Notes on the vocalizations of White-tailed Leaf-warbler (Phylloscopus davisoni)
}

Peter Boesman

In the following we briefly analyze and compare voice of the different races of White-tailed Leaf-warbler (Phylloscopus davisoni). We also try to quantify the extent of any vocal differences using the criteria proposed by Tobias et al. (2010), as a support for taxonomic review. We have made use of sound recordings available on-line from Xeno Canto (XC) and Macaulay Library (ML).

A comparison of song per race, illustrated with sonograms:

\section{davisoni}

Song is typically a subphrase repeated 2 or 3 times, sometimes preceded by an introductory note. The repeated subphrase is typically either rising or falling in pitch.
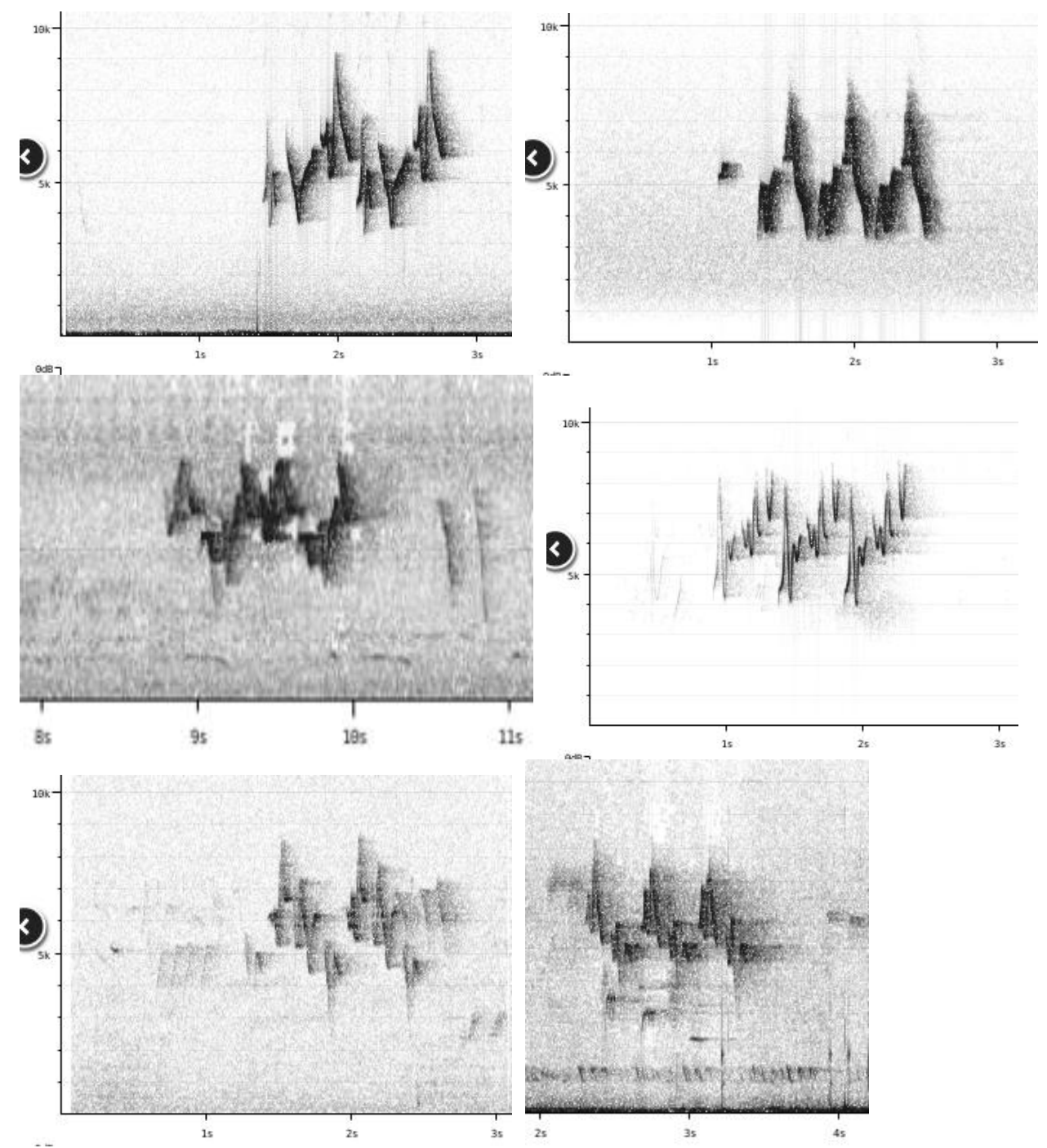


\section{intensior}

Song has a clear repetitive pattern, rather like davisoni.
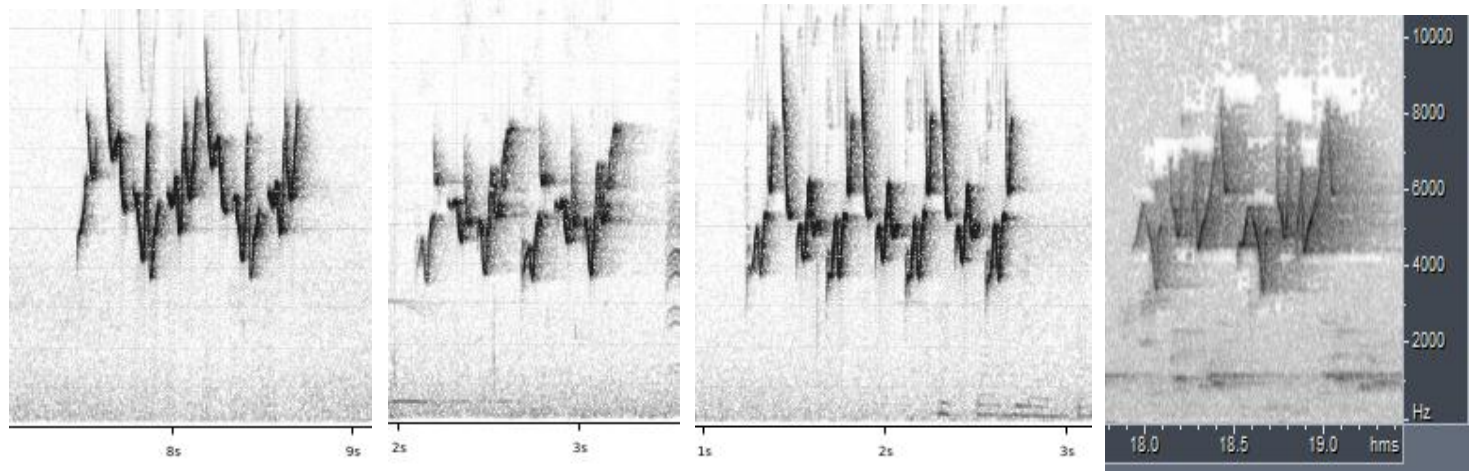

Other races:

Song of other races is a warbled phrase of about $1.5 \mathrm{~s}$ long, lacking a clear repetitive pattern. disturbans
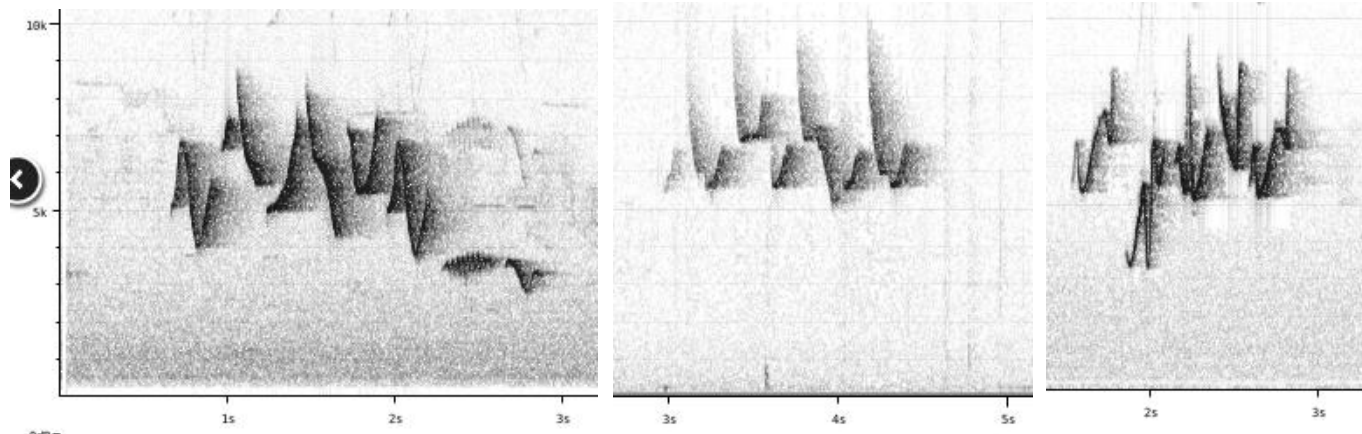

ogilviegranti

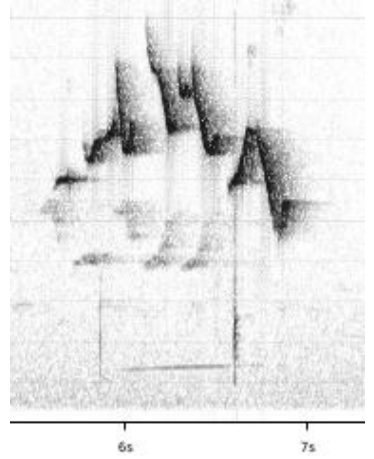

klossi
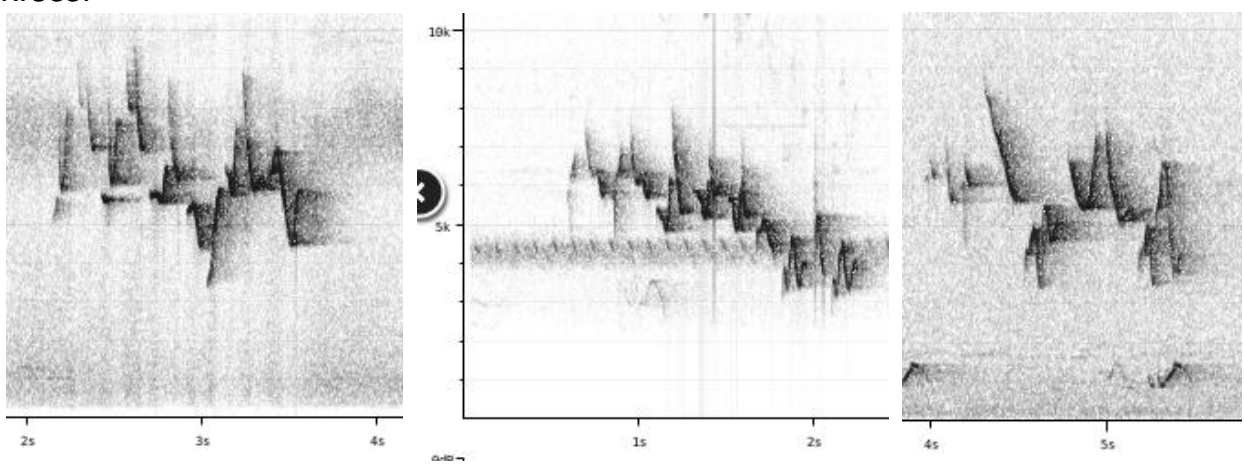

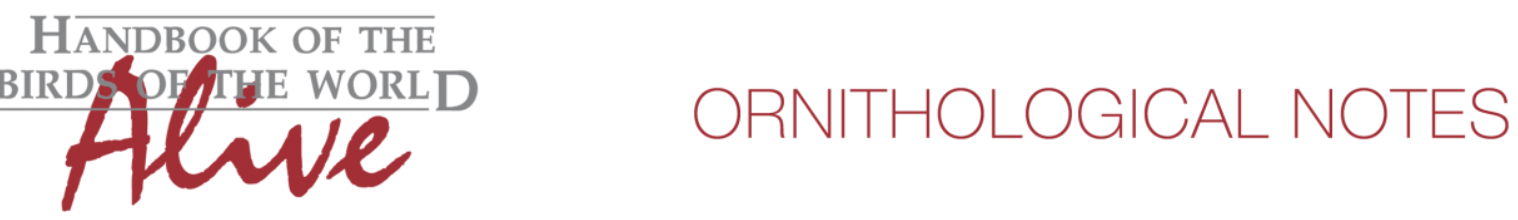

It is thus seemingly more logical to group intensior together with davisoni.

If done so, then the repetitive phrases (number of repeats per song baud, score 3 ) and duration of shortest unique phrase (score 2) would lead to a total vocal score of about 5. If davisoni stays monotypic, there is hardly any difference with the remainder due to the intensior voice...

This note was finalized on 29th February 2016, using sound recordings available on-line at that moment. We would like to thank in particular the many sound recordists who placed their recordings for this species on XC and ML.

\section{References}

Tobias, J.A., Seddon, N., Spottiswoode, C.N., Pilgrim, J.D., Fishpool, L.D.C. \& Collar, N.J. (2010). Quantitative criteria for species delimitation. Ibis 152(4): 724-746.

\section{Recommended citation}

Boesman, P. (2016). Notes on the vocalizations of White-tailed Leaf-warbler (Phylloscopus davisoni). HBW Alive Ornithological Note 425. In: Handbook of the Birds of the World Alive. Lynx Edicions, Barcelona. (retrieved from http://www.hbw.com/node/1254399 on 8 December 2016). 